\title{
A prospective study of benign breast disorders at B.P. Koirala Institute of Health Sciences, Dharan, Nepal
}

\author{
Kumar A. ${ }^{1}$, Snehlata ${ }^{2}$, Kaur N. ${ }^{3}$ \\ ${ }^{1}$ Dr. Abhishek Kumar, General Surgery, ${ }^{2}$ Dr. Snehlata, Obstetric \& Gynaecology, both authors are Specialist Doctor at Sadar \\ Hospital Hazaribag \& Visiting Consultant at Vandana Nursing Home, Shivpuri, Hazaribagh, Jharkhand, India, ${ }^{3}$ Dr. Navneet \\ Kaur, Professor, Department of General Surgery, BPKIHS, Dharan, Nepal.
}

Corresponding Author: Dr. Snehlata, Obstetric \& Gynaecology, Specialist Doctor at Sadar Hospital Hazaribag \& Visiting Consultant at Vandana Nursing Home, Shivpuri, Hazaribagh, Jharkhand, India. Email: sneha91@ymail.com

\begin{abstract}
Objectives: To know the spectrum of benign breast disorders presenting to Surgery outpatient department or emergency at BPKIHS. Aim: To study the medical or surgical treatment modalities in benign breast disorders, To find out the outcome of treatment of benign breast disorders. Methods: Inclusion Criteria: One hundred and sixty-one patients of either sex were randomly assigned found to have breast related symptoms like pain, lump, nipple discharge or fever, were included in the study. Male patients presenting with gynaecomastia also included. With clinical or histopathological evidence of malignant breast disease excluded. Included following investigations1.Total counts and differential, 2. Chest X-ray, ECG, 3. Breast abscess diagnosed on clinical ground, 4. FNAC, 5. USG of breast, 6. Mammography of the breast, 7. Imprint cytology. Management: either conservatively or surgically. follow up at one week, one month, three month and explained importance of follow up. Result: The mean age were 15-66 years, 70\% were 20-40 years, 96.9\% were females and 3.1\% male, 83.9\% married \& $16.1 \%$ were unmarried. The duration of illness ranged from 2days to 4380 days with mean of 258.99 days. Acute illness $(n=70)$ had mean of 5.11 days and chronic illness $(n=91)$ had a mean of 454.27 days, complained of lump in breast $(n=149)$ followed by pain $(n=140)$. Discharge from nipples in 5 patients, fever in 44 patients. One with retraction of nipple. Both pain and lump in 127 cases whereas 13 had only mastalgia and 22 had only lump in breast. Conclusion: This is understandable and to allay their fear, an understanding of benign breast disorder is essential Hence, in a country like Nepal, education regarding breast self-examination and proper follow up is highly recommended so that early treatment is sought.
\end{abstract}

Keywords: Benign breast disorders, Breast cancer, Breast self-examination

\section{Introduction}

Most complaints related to the breast are benign in nature. In spite of this most women with breast complaints assume the worst when a new problem is discovered. But to help allay these fears an understanding of the benign breast disorders is essential. Benign Breast Disorders (BBD) can be defined to include all those breast diseases which are not malignant. BBD have not generated much interest to both the clinicians as well as the researchers. Over the last century much data has come up for BBD but it is miniscule as compared to the data bank of Breast Cancer.

This scattered data of BBD has now undergone attempts at compilation and analysis and the results started to show some evidences that help to guide the clinician in his/her practice. BBD has been used as the 'portmanteau' where all benign lesions are dumped and thereby blurring all

Manuscript Received: $17^{\text {th }}$ November 2019

Reviewed: $27^{\text {th }}$ November 2019

Author Corrected: $4^{\text {th }}$ December 2019

Accepted for Publication: $7^{\text {th }}$ December 2019 distinction between them [1]. This includes a whole gamut of diseases - developmental (aplasia, hypoplasia, gynaecomastia etc), inflammatory (mastitis - specific \& nonspecific, abscess, fat necrosis, Mondor's disease, etc), benign tumors (adenoma, papilloma, hamartoma, etc), yet there are a formidable number of lesions in which plenty of discrepancy regarding etiopathogenesis, presentation, pathological picture, behaviour, treatment options and response to therapy and varied prognosis. The clinico pathological and clinico radiological correlations have been attempted to identify a particular disease state to formulate a working strategy for management.

Explanation and encoding through pathological terms for clinical correlation is complex and individualistic the same disease is differently represented histologically by different workers. These have resulted in accumulation of more than 40 names that more or less depict the same disease and these are the ones to be clubbed under the 


\section{Original Research Article}

banner of BBD. 'Fibrocystic Disease' is widely used and for long has been the accepted terminology for such diseases but Hutter put forth his ideology that this was nothing but varied physiological responses in the life span of the female breast and that $90 \%$ of the women would have histopathological changes of fibrocystic disease and it would be better to say "Good bye to Fibrocyctic Disease" [2]. Breast pain is known as mastalgia and can be caused by a number of different "diseases".

The same is true of benign breast lumps, nipple disorders and indeed infections. However, in many cases what brings a woman to see her doctor is no more than an Aberration of Normal Breast Development and Involution (ANDI).

The term ANDI is useful, since it implies that most of the benign disorders are in fact only physiological (i.e. Normal) extremes- but still normal. When a benign problem goes beyond the ANDI category, it can truly be considered as an abnormality, and in these cases, treatment may be required [3-10].

\section{Material and Methods}

Duration: One year from February 2006 to February 2007.

Type of study: Prospective study.

Sampling method: Random selection of case related patient.

Sample size calculation: Master chart for the calculation of sample size

Inclusion criteria: All female patients coming to BPKIHS Surgery Outpatient Department and emergency who were found to have breast related symptoms like pain, lump, nipple discharge or fever, were included in the study. Male patients presenting with gynaecomastia were also included in this study.

Exclusion criteria: Patients presenting with obvious clinical signs of malignancy like; hard lumps, fixity to skin or chest wall, fungating mass, previous history of carcinoma breast or with a lump proved on investigations to be carcinoma breast were excluded from the study.

Data collection procedure: in lab. Data analysis: statistically done.
Ethical consideration\& permission taken from the patient and department of surgery.

Clinical evaluation: Detailed history and clinical examination was done. Many Symptoms at the time of presentation like Pain, Onset, its duration, intensity, nature of pain, aggravating and relieving factors, relation to menstrual cycle were noted. Lump in breast Its duration, site and characteristics, Discharge from nipples duration and characteristics, Fever duration of fever was noted. Retraction of nipple whether present or not Past history ofany breast biopsy was noted to exclude carcinoma breast or recurrent BBD like fibroadenosis.

\section{Diagnostic work-up with following investigations:}

1.Total counts and differential counts

2.Chest X-ray and ECG

3. Pus was sent for culture

4. FNAC \& Excisional biopsy

5. Ultrasound of breast

6. Mammography of the breast

7. Imprint cytology for discharge from the nipples or any ulcerative lesion over breast.

Management: Conservative management: Mastalgia: with oral diclofenac sodium $50 \mathrm{mg}$ for symptomatic pain relief and Vitamin E 400mg twice daily for one month. Granulomatous mastitis: with oral diclofenac sodium $50 \mathrm{mg}$ for symptomatic pain relief and Vitamin E 400mg once daily for one month. All patients with cyclical nodularity were reassured and followed up with regular clinical breast examination All patients with physiological nipple discharge were kept on conservative management.

Surgical management: Breast Abscess, Fibroadenoma more than $2 \mathrm{~cm}$ in size or less than $2 \mathrm{~cm}$ but causing lot of patient anxiety, Major Duct ectasia, Benign lumps reported as indeterminate on FNAC, Gynaecomastia.

Necessity and importance of regular follow: up was explained to patient and the relatives. Outcome of treatment was accessed by patient's symptoms and clinical exam findings on follow up of patients. Admitted patients were daily examined complains and clinical findings were noted and treated accordingly. Follow up patients were asked to follow up at one week, one month and three month and explained about importance of follow up.

\section{Results}

Clinical Profile- Age Distribution: The mean age of the patients was 28.68 \pm 9.64 years and the range were 15-66 years. More than $70 \%$ patients belonged to age group between $20-40$ years (Table 1 ). 


\section{Original Research Article}

Table-1: Age distribution of patients.

\begin{tabular}{|c|c|c|}
\hline Age (years) & Number of patients (n) & Percentage \\
\hline $15-20$ & 27 & 16.77 \\
\hline $21-25$ & 49 & 30.43 \\
\hline $26-30$ & 34 & 21.11 \\
\hline $31-35$ & 18 & 11.18 \\
\hline $36-40$ & 17 & 10.55 \\
\hline $41-45$ & 7 & 4.34 \\
\hline $46-50$ & 3 & 1.86 \\
\hline$>50$ & 6 & 3.72 \\
\hline Total & $\mathbf{1 6 1}$ & $\mathbf{1 0 0}$ \\
\hline
\end{tabular}

Sex distribution- In this study, out of 161 patients, 156 were females (96.9\%) and 5 were males (3.1\%) (Table 2).

Table-2: Sex distribution.

\begin{tabular}{|c|c|c|}
\hline & No of patients & Percentage \\
\hline Males & 5 & $3.10 \%$ \\
\hline Females & 156 & $96.90 \%$ \\
\hline Total & $\mathbf{1 6 1}$ & $\mathbf{1 0 0 \%}$ \\
\hline
\end{tabular}

Marital status: In this study, out of 161 patients, 135 were married (83.9\%) and $26(16.1 \%)$ were unmarried (Table 3$)$.

Table-3: Marital status.

\begin{tabular}{|c|c|c|}
\hline Marital status & No of patients & Percentage \\
\hline Married & 135 & $83.90 \%$ \\
\hline Unmarried & 26 & $16.10 \%$ \\
\hline Total & $\mathbf{1 6 1}$ & $\mathbf{1 0 0 \%}$ \\
\hline
\end{tabular}

Duration of illness: In the study, the duration of illness ranged from 2 days to 4380 days with mean of 258.99 days. Acute illness $(n=70)$ had mean of 5.11 days and chronic illness $(n=91)$ had a mean of 454.27 days (Table 4$)$.

Table-4: Duration of illness.

\begin{tabular}{|l|c|c|c|}
\hline & Range & Mean & Total \\
\hline Acute & $2-30$ days & 5.11 & 70 \\
\hline Chronic & $31-4380$ days & 454.27 & 91 \\
\hline
\end{tabular}

Patients complains: Maximum of the patients complained of lump in breast $(n=149)$ followed by pain $(n=140)$. Discharge from nipples was present in 5 patients whereas fever was present in 44 patients. One patient presented with retraction of nipple (Table 5).

Both pain and lump was present in 127 cases whereas 13 had only complaints of mastalgia and 22 had only complaints of lump in breast. Discharge from nipples was associated with pain alone in 4 cases and lump alone in 1 case whereas it was associated with both pain and lump in only 1 case.

Table-5: Patients complaints.

\begin{tabular}{|c|c|c|}
\hline Complaints & No of patients & Percentage \\
\hline Lump & 149 & $92.50 \%$ \\
\hline Pain & 140 & $87 \%$ \\
\hline Fever & 44 & $27.30 \%$ \\
\hline Discharge from nipples & 7 & $4.34 \%$ \\
\hline Retraction of nipples & 1 & $0.60 \%$ \\
\hline
\end{tabular}




\section{Original Research Article}

History of previous intervention- Out of 161 patients, 3 patients had undergone surgical intervention in the past. Fine needle aspiration cytology was done in 1 case, incision and drainage was done in 1 case and excisional biopsy was done in 1 case (Table 6).

Table-6: Previous intervention.

\begin{tabular}{|c|c|c|}
\hline Diagnosis & No of patients & Percentage \\
\hline FNA & 1 & 0.6 \\
\hline I \& D & 1 & 0.6 \\
\hline Excisional biopsy & 1 & 0.6 \\
\hline No intervention & 158 & 98.1 \\
\hline
\end{tabular}

Clinical Findings: General status of all the patients were average. Size of the breast was enlarged in 27 patients and swelling was present in 68 cases. Ulceration over breast in 4 cases. Erythema and raised local temperature were present in all cases of breast abscesses $(n=68)$. Retraction of nipple was present in 3 cases whereas palpable lump was present in 145 patients. Out of 161 patients, 55 were lactating and others were non lactating. Discharge from nipples was present in 7 cases out of which discharge was pus in 4 cases and discharge was blood in 3 cases. Anterior and central group of axillary lymph nodes were positive in one patient.

Investigations: Baseline investigation was done in all patients undergoing surgery $(\mathrm{n}=126)$ and all were within normal limit.

Ultrasonography: USG was done in 19 cases suggestive of fibroadenosis in 7, fibroadenoma in 5, major duct dilatation in 5 and simple cyst in 2 cases (Table 7).

Table-7: Ultrasonography.

\begin{tabular}{|c|c|c|}
\hline Diagnosis & No of patient & Percentage \\
\hline Fibroadenosis & 7 & 4.34 \\
\hline Fibroadenoma & 5 & 3.10 \\
\hline Major duct dilatation & 5 & 3.10 \\
\hline Simple cyst & 2 & 1.24 \\
\hline
\end{tabular}

Mammography: Mammography was done in 20 patients. Seven showed fibroadenosis, 5 had fibroadenoma, 5 had major duct dilatation. Mammography showed normal breast, resolving abscess, and simple cyst in one case each (Table 8).

Table-8: Mammography.

\begin{tabular}{|l|c|c|}
\hline Diagnosis & No of patient & Percentage \\
\hline Fibroadenosis & 7 & 4.34 \\
\hline Fibroadenoma & 5 & 3.10 \\
\hline Major duct dilatation & 5 & 3.10 \\
\hline Normal breast & 1 & 0.62 \\
\hline Resolving abscess & 1 & 0.62 \\
\hline Simple cyst & 1 & 0.62 \\
\hline
\end{tabular}

Fine Needle Aspiration Cytology (FNAC): Fine needle aspiration cytology was advised to 70 patients having firm lump on palpation.

Three patients refused for intervention, FNAC revealed fibroadenoma in 35 cases, fibroadenosis in 22 cases, lipoma in 2 cases, reactive lymphadenitis in 2 cases, simple cyst in 2 cases, apocrine ductal hyperplasia in 2 cases. One case of granulomastitis and infected cyst was diagnosed on FNAC (Table 9). 


\section{Original Research Article}

Table-9: FNAC.

\begin{tabular}{|l|c|c|}
\hline Diagnosis & No of patient & Percentage \\
\hline Firm lump on palpation & 70 & 43.47 \\
\hline Patients refused & 3 & 21.73 \\
\hline Fibroadenoma & 35 & 13.66 \\
\hline Fibroadenosis & 22 & 1.24 \\
\hline Lipoma & 2 & 1.24 \\
\hline Reactive lymphadenitis & 2 & 1.24 \\
\hline Simple cyst & 2 & 1.24 \\
\hline Apocrine ductal hyperplasia & 2 & 0.62 \\
\hline Granulomastitis and infected cyst & 1 & 24 \\
\hline
\end{tabular}

Imprint cytology: Imprint cytology was done in 5 patients out of whom 4 had ductal ectasia (2.48\%) and 1 had apocrine ductal hyperplasia $(0.62 \%)$.

Excisional biopsy: Excisional biopsy was done in one case of fibroadenoma. $(0.62 \%)$

Pus culture: Pus for culture and sensitivity was sent in all 69 cases of breast abscess. Staphylococcus aurous ( $\mathrm{n}=61$ ), Coagulase Negative Staphylococcus $(n=5)$, E. coli $(n=1)$ were the organism grown whereas two samples were sterile after 48 hours of incubation period. No case had multiple colonization on culture (Table 10).

Table-10: Pus culture.

\begin{tabular}{|c|c|c|}
\hline Diagnosis & $\begin{array}{c}\text { No of Patient 69 out of 161 patients } \\
\text { (cases of breast abscess n=69) }\end{array}$ & Percentage \\
\hline Staphylococcus aurous & 61 & 37.8 \\
\hline Coagulase Negative Staphylococcus & 5 & 3.10 \\
\hline e.coli & 1 & 0.62 \\
\hline sterile after 48 hours of incubation period & 2 & 1.24 \\
\hline multiple colonization on culture & No & \\
\hline
\end{tabular}

Colony pattern of Organism :All the organism grown were sensitive to Amikacin, sensitivity to Cefotaxim was present in 64 samples (39.75\%), sensitivity to Ciprofloxacin was present in 7 samples (4.34\%), sensitivity to Ofloxacin was present in 61 samples $(37.88 \%)$, sensitivity to Erythromycin was present in 4 samples $(2.48 \%)$, sensitivity to Penicillin was present in 6 samples $(3.72 \%)$.

Sensitivity pattern: Cross sensitivity to Cefotaxim, Cefotaxim and Ofloxacin/ Ciprofloxacin was present in 61 samples (37.88\%)

Diagnosis: Of a total of 161 patients, maximum patients had breast abscesses $(n=69)$.

Second most common disease was Fibroadenosis $(n=31)$ followed by Fibroadenoma $(n=29)$., Mastalgia ( $n=10)$, Major duct ectasia $(n=7)$, Antibioma $(n=3)$, Lipoma $(n=2)$, Infected cyst $(n=2)$, Gynaecomastia $(n=2)$, Infected cyst $(n=1$,) Benign Apocrine Metaplasia $(n=1)$, Granulomatous mastitis $(n=1)$, Reactive lymphadenopathy $(n=1)$, Sinus breast $(n=1)$ and Soar nipple $(\mathrm{n}=1)$ (Table 11). 


\section{Original Research Article}

Table-11: Diagnosis.

\begin{tabular}{|l|c|c|}
\hline Diagnosis & Number of patients & Percentage \\
\hline Breast abscess & 69 & $42 \%$ \\
\hline Fibroadenosis & 31 & $19.25 \%$ \\
\hline Fibroadenoma & 29 & $6.21 \%$ \\
\hline Mastalgia & 10 & $4.34 \%$ \\
\hline Major duct ectasia & 7 & $1.90 \%$ \\
\hline Antibioma & 3 & $1.20 \%$ \\
\hline Lipoma & 2 & $1.20 \%$ \\
\hline Simple cyst & 2 & $1.20 \%$ \\
\hline Gynaecomastia & 2 & $0.60 \%$ \\
\hline Infected cyst & 1 & $0.60 \%$ \\
\hline Benign Apocrine Metaplasia & 1 & $0.60 \%$ \\
\hline Granulomatous mastitis & 1 & $0.60 \%$ \\
\hline Reactive lymphadenopathy & 1 & $0.60 \%$ \\
\hline Sinus breast & 1 & $0.60 \%$ \\
\hline Soar nipple & 1 & $\mathbf{1 0 0 \%}$ \\
\hline Total & $\mathbf{1 6 1}$ & \\
\hline
\end{tabular}

Among males, two had gynaecomastia, whereas Fibroadenoma, Fibroadenosis and Reactive lymphadenopathy was present in one patient each.

Side Affected: Right side of breast was affected more $(n=81)$ than left side $(n=59)$, and bilateral disease was also seen in significant no of patients $(\mathrm{n}=21)$ (Table 12).

Table-12: Diagnosis.

\begin{tabular}{|l|c|c|}
\hline Diagnosis & No of patient & Percentage \\
\hline Right side of breast & 81 & 50.31 \\
\hline Left side of breast & 59 & 36.64 \\
\hline Bilateral breast & 21 & 13.04 \\
\hline
\end{tabular}

\section{Treatment}

- Management included both medical and surgical interventions.

- All cases of breast abscess $(n=69)$ underwent incision and drainage under general anesthesia. Cloxacillin 500mg four times a day was given orally for 48 hours and was later changed according to antibiotic sensitivity reports and oral diclofenic sodium $50 \mathrm{mg}$ three times daily, was given for a minimum of three days.

- Antibioma $(\mathrm{n}=3)$ was managed successfully with ciprofloxacin $500 \mathrm{mg}$ twice daily orally for seven days and oral diclofenic sodium 50mg thrice daily for five days.

- Out of 29 cases of fibroadenoma, 27 had excision. Two cases where lump was less than $1 \mathrm{~cm}$ in size were treated with oral diclofenic sodium 50mg to be taken for three days and if required. Vitamin E 400mg once daily for one month was added on first follow up as patient had complains of pain.

- Out of 31 cases of Fibroadenosis, excision was done in 14 cases. Others who did not agree for surgery were given oral diclofenac sodium 50mg for symptomatic pain relief and Vitamin E 400mg once daily for one month, Two patients who did not respond to above mentioned treatment were given Danazole 100mg thrice daily, starting at $100 \mathrm{mg}$ once daily dose for three months and later were free of symptoms. 


\section{Original Research Article}

- All cases of cyclic mastalgia $(\mathrm{n}=10)$ were given reassurance and were advised to wear proper breast supporting undergarments. Danazole $100 \mathrm{mg}$ thrice daily, starting at $100 \mathrm{mg}$ once daily dose for three months to all patients and vitamin E 400mg once daily for a minimum period of one month. Vitamin E was given for a maximum period of three months in four patients.

- Out of 7 patients with major duct dilatation, 6 underwent Hadfield's operation, where as one case was managed successfully conservatively with oral diclofenic sodium 50mg thrice daily for five days and oral ciprofloxacin 500mg twice daily for seven days.

- Both the patients with Simple cyst measuring less than $1 \mathrm{~cm}$ in size underwent ultrasonographic guided needle aspiration and were advised oral diclofenac sodium $50 \mathrm{mg}$ to be taken only if pain persisted.

- One patient with infected cyst was treated with needle aspiration and with oral diclofenac sodium 50mg thrice daily for three days and oral ciprofloxacin 500mg twice daily for seven days as patient was not ready for enucleation and later had no complains on second follow up.

- Two patients with lipoma in breast were treated successfully with surgical excision.

- One case of gynaecomastia was treated surgically whereas other was reassured.

- One cases of sinus breast underwent excision.

- A single case of soar nipple was taught about hygiene and treated successfully with oral diclofenic sodium 50mg thrice daily for three days and oral ciprofloxacin 500mg twice daily for seven days.

- One case each of Benign Apocrine Metaplasia and Granulomatous mastitis was treated successfully with oral vitamin E $400 \mathrm{mg}$ once daily for one month and oral diclofenic sodium $50 \mathrm{mg}$ for symptomatic relief of pain.

- One patient with reactive lymphadenopathy was treated successfully with oral ciprofloxacin $500 \mathrm{mg}$ twice daily for seven days and oral diclofenac sodium 50mg thrice daily for five days.

Hospital admission and duration of stay: Out of 161 patients, 101 (62.7\%) patients had a hospital stay of less than twelve hours, while $21(13.15 \%)$ had to stay for more than 12 twelve. Maximum stay was six days in one patient with fibroadenoma.

Patients satisfaction and follow-up: Out of 161 patients, only one hundred patients had come in first follow-up, thirty-eight in second follow-up and twenty-five in third follow-up. One hundred and three patients felt satisfied after their visit to hospital. Satisfaction level of rest could not be assessed as mainly due to patients loss in follow-up

follow up: On first follow up, 11 out of 100 patients mainly complained of pain and discharge. On second follow up, 3 out of 38 patients complained of wound site gapping. There was no complains of any patients $(n=25)$ on their third follow up.

\section{Discussion}

A total of one hundred and sixty-one patients who had complains of symptoms of pain, lump and nipple discharge were enrolled for this study. In the present study, it was found that Breast abscess ( $\mathrm{n}=69$ i.e. $42 \%)$ was the most prevalent of all benign breast diseases (BBDs) followed by Fibroadenosis ( $\mathrm{n}=31$ i.e19.25\%).

Studies to determine the incidence of breast problems have been conducted in Nepal. Most of the studies found benign breast disease to be the leading problem in Nepal among which Fibroadenoma is the commonest $[11,12,13]$. This difference might be due to patients belonging to hilly regions and distant village, who were ill - literate and had poor hygiene. A study conducted in Nepal gung Medical College [14] in the year 2003 in a surgical outpatient department showed that benign breast diseases (BBD) were the commonest lesions (93.2\%) of all the cases presenting with breast problems, while malignant lesions were infrequent $(6.8 \%)$. Among BBD the commonest benign conditions were fibro adenomas, $32.57 \%$, followed by breast abscess, $24.19 \%$, Aberration of Normal Development and Involution (ANDI) $16.63 \%$ and gynaecomastia (11.34\%). Only eighteen cases $(6.8 \%)$ were malignant lesions. In this study, the commonest ages for Fibroadenoma were between 20 and 40 years old.

Age and gender-The youngest patient in the present study was 15 years and the eldest was 66 years of age with a mean of $28.68 \pm 9.64$ years. Twenty-one to twenty-five was the most common age group being affected by BBDs $(30.43 \%)$ and $51.54 \%$ patients belonged to age group twenty-one to thirty. In a similar study Sandhya P Iyer and M P Gure found that maximum percentage of patients were of age group 20-30 years having BBD (35\%) [15]. 


\section{Original Research Article}

Clinical Profile-In the present study, the main complain of the patients was lump (92.50\%) followed by pain in the breast (87\%). Both pain and lump was present in 127 patients $(80.12 \%)$. Discharge from nipples was present in $7(4.34 \%)$ cases whereas fever in $44(27.30 \%)$ and retraction of nipples in $1(0.6 \%)$ patient. Swelling or breast lump was predominant complain in breast abscess, fibroadenoma and fibroadenosis Duration of pain varied from 2days to 12.5 years. A similar study done by Sandhya P Iyer and M A Gore at department of Surgery, LTMGH and Medical College, Mumbai reveals 3 main symptoms for benign breast diseases.

There was lump seen in $100 \%$ of patients with benign breast disease, pain in 50\% and discharge in 15\% [15]. Swelling or breast lump was predominant complain in fibroadenoma, fibroadenosis, cystosarcomaphylloides, lipoma and chronic mastitis. Lump associated with pain was seen in fibroadenosis, breast abscess, tuberculous mastitis and chronic mastitis. Pain (50\% of patients) was the predominant symptom in breast abscess. Discharge was seen in $15 \%$ of patients $[15,16,17$,$] .$

Treatment and outcome of treatment: In the present study all the breast abscess underwent incision and drainage and only a very few patients had complained of pain and discharge on first visit. Out of twenty-nine cases of fibroadenoma, 27 had excision whereas two cases were treated successfully with oral diclofenic sodium and vitamin E. Cyclic mastalgia advised to wear proper breast supporting undergarments and oral diclofenic sodium for a minimum of 3 days and oral Vitamin E $400 \mathrm{mg}$ once daily for a minimum period of one month showed hundred percent improvements. Surgical and conservative management in cases of fibroadenosis showed similar results in the present study.

A study conducted in Nepalgung Medical College in the year 2003 in a surgical outpatient department showed that fibroadenoma underwent excision and breast abscess underwent incision and drainage and there was 100\% success after treatment [13]. Ultrasonographic guided aspiration of breast abscess is the treatment of choice in the developed countries showing about $98 \%$ outcome $[18,19,20]$. In the U.K. clinical experience the overall response rate to mastalgia was $44 \%$ in cyclical pain and $27 \%$ in non-cyclical pain. Danazol (overall response $70 \%$ in cyclical mastalgia and $31 \%$ in non-cyclical pain), bromocriptine (overall response $47 \%$ in cyclical mastalgia and $20 \%$ in non-cyclical pain) and tamoxifen (overall response $75 \%$ differentiation) were reserved for treatment failures [14]. Patients not getting Danazole, tamoxifen, bromocriptine or evening primrose oil in the present study showed equal response as compared to those receiving these drugs in other studies.

\section{Conclusion}

Hence, in a country like Nepal, education regarding breast self-examination and reassurance is the first step in treating benign breast lesions. proper follow up is highly recommended so that early treatment is sought.

\section{What the study adds to the existing knowledge?}

The present study inferred that in a country like Nepal, education regarding breast self-examination and proper follow up is highly recommended so that early treatment is sought.

\section{Author's contribution}

Dr. Abhishek Kumar: Study design, concept

Dr. Snehlata: Manuscript preparation

Dr. Navneet Kaur: Data analysis

Funding: No funding sources

Conflict of interest: None declared

Ethical Approval: This study was approved by the Institutional Ethics Committee

\section{References}

1. Agrawal V. Fibrocystic Disease. In: Agarwal N, Suneja A. Female Breast Gynaecologist Viewpoint. 2000, Jaypee, FOGSI Publication, Delhi, 178-190.

2. Hutter RVP. Goodbye to "Fibrocystic disease" N Engl J Med. 1985; 312:179-181. doi: 10.1056/NEJM 1985011 73120311 .

3. Sharma A, Bandari R, Gilbert D, Sharma A.K. Benign and malignant breast disease presenting to Bhaktapur Cancer Hospital. Kathmandu Univ Med J. (KUMJ). 2005; 3 (4):384-387.

4. Smith RA, Saslow D, Sawyer KA, Burke W, Costanza ME, Evans WP 3rd, et al. American Cancer Society Guidelines for Breast Cancer Screening: Update 2003. CA Cancer J Clin. 2003;53(3):141-169. doi: https://doi.org/ 10.3322/ canjclin.53.3.141.

5. Caleffi M, Filho DD, Borghetti K, Graudenz M, Littrup PJ, Freeman-Gibb LA, et al. Cryoablation of benign breast tumors: evolution of technique and technology. Breast 2004;13(5):397-407. doi:https://doi.org/10.1016/j. breast. 2004. 04.008.

6. Kelsey JL, Gammon MD. Epidemiology of breast cancer. Epidemiol Rev 1990; 12(1):228-240. doi: https:// doi.org/10.1093/oxfordjournals.epirev.a036056. 


\section{Original Research Article}

7. Chinson WB, Thomas DB, Hamlin WB et al. Risk of breast cancer in women with benign breast lesion. J Natl Cancer Inst. 1980;65(1):13-20.

8. Wang DY, Fentiman IS. Epidemiology and endocrinology of benign breast disease. Breast Cancer Res Treat. 1985;6(1):5-36.

9. Drukker BH. Fibrocystic Change of Breast. In: Pitkim RM and Scott JR (eds). JB Lippencott Company, Philadelphia, Pennsylvania, 1994,37(4): 903-915.

10. Ernster VL. The Epidemiology of Benign Breast Disease. Epidemiol Rev. 1981;3(1):184-202. doi: https:// doi.org/10.1093/oxfordjournals.epirev.a036233

11. Itzgibbons PL, Henson DE, Hutter RV. Benign breast changes and the risk for subsequent breast cancer: an update of the 1985 consensus statement. Cancer Committee of the College of American Pathologists. Arch Pathol Lab Med. 1998;122(12):1053-1055.

12. Khan S, Kapoor A.K, Khan I.U. Shrestha G.B. Singh $\mathrm{P}$, Prospective study of pattern of breast disease at Nepalganj Medical College, Nepal. Kathmandu Univ Med J (KUMJ).2003;1(2):95-100.

13. Arnelli R, Squartini F. Fibrocystic condition and "at risk" lesions in asymptomatic breasts: a morphologic study of postmenopausal women. Clin Exp Obstet Gynecol. 1991;18(4):271-279.
14. Shukla HS, Kumar S. Benign Breast Disorders in Nonwestern Populations Part-II - Benign Breast Disorders in India. World J Surg. 1989;13(6):746-749.

15. Iyer SP, Gore MA. Epidemiology of benign breast diseases in females of childbearing age group. Department of Surgery, LTMGH and Medical College, Sion, Mumbai. Bombay Hospital J. 2000;42(1):141-146.

16. Wazer DE, Gage I, Horner MJ, Krosmick SH, Schmid C. Age related differences with non-palpable breast carcinomas. Cancer. 1996;78(7):1432-1437.

17. La Vecchia C, Parazzini F, Franceschi S, Decarli A. Risk factors for benign breast disease and their relation with breast cancer risk. Pooled information from epidemiologic studies. Tumori. 1985;71(2):167-178.

18. Friedenreich CM, Bryant HE, Alexander F, Hugh J, Danyluk J, Page DL Risk factors for benign proliferative breast disease. Int J Epidemiol. 2000;29(4):637-644. doi: https://doi.org/10.1093/ije/29.4.637.

19. Santen RJ, Mansel R. Benign Breast Disorders. New Eng J Med. 2005;353(3):275-285. doi: 10.1056/NEJMra 035692 .

20. Markopoulos C, Kouskos E, Kontzoglou K, Gogas G, Kyriakou V, Gogas J.. Breast cancer in ectopic breast tissue. Eur J Gynaecol Oncol. 2001;22(2):157-159.

\section{How to cite this article?}

Kumar A, Snehlata, Kaur N. A prospective study of benign breast disorders at B.P. Koirala Institute of Health Sciences, Dharan, Nepal. Surgical Update: Int J surg Orthopedics.2019;5(5):346-354.doi:10.17511/ijoso.2019.i05.06 